\title{
Macro and micro analysis on deformation characteristics of fine sand under different groundwater table change
}

\author{
Tianrong Huang ${ }^{1 *}$, Yaoru $\mathrm{Lu}^{2}$, Xuefeng Wang ${ }^{3}$, Qiushi Fu ${ }^{4}$, Yu Wang ${ }^{1}$, Yuanzhao Chen ${ }^{5}$ \\ ${ }^{1}$ School of civil and traffic engineering, Shanghai Urban Construction Vocational College, Shanghai, 200438, China \\ 2 Department of Geotechnical Engineering, Tongji University, Shanghai, 200093, China \\ ${ }^{3}$ School of traffic engineering, Shanghai Maritime University, Shanghai, 201306, China \\ ${ }^{4}$ Shanghai Construction No.2 (Group) Co., Ltd., Shanghai, 200090, China \\ ${ }^{5}$ North China University of Water Resources and Electric Power, Zhengzhou, 450045, China
}

\begin{abstract}
By using the samples of fine sand in Shanghai's seventh layer, creep tests were performed to investigate the deformation characteristics of fine sand under different groundwater table change. It was revealed that the creep of fine sand is closely related to groundwater table change: when the effective force caused by groundwater table change is smaller than pre-consolidation force, the deformation is mainly elastic. When effective force caused by groundwater table change is bigger than pre-consolidation force, the compression deformation is large and the rebound is small; and the deformation is mainly viscoelastic plastic when equal to pre-consolidation stress. Through the scanning electron microscope (SEM) analysis it was found that creep of fine sand is dominated by the slip of particles, not by the breaking of particles. And the fine sand particles are squeezed under the load induced by the groundwater table change, and the particles slide along the indirect contact surface of the particles, resulting in the continuous adjustment of position and relative displacement. Mercury injection test shows that the pore size distribution of fine sand has little change before and after the test.
\end{abstract}

\section{Introduction}

During construction of deep foundation pit, dewatering needs to be implemented to ensure the safety excavation. Dewatering often leads to the redistribution of underground stress field, which inevitably leads to soil disturbance and deformation. In general, soil deformation includes primary consolidation and creep. The land subsidence induced by dewatering in deep foundation pit also involves the creep of soil. In order to reveal the mechanism of creep, many experts and scholars have carried out a variety of researches. Xu and Cui developed a fractional derivative model that describes the timedependent behaviour of Shanghai marine clay [1]. Li and Yang studied the unsaturated creep behaviour of reticulate red clay under matric suction through a series of isotropic creep tests with different matric suction level [2]. Zhu et al focused on the quantitative description of the evolution of creep coefficient with both soil density and soil structure under 1D compression [3]. Tim studied the performance of the variable rate of strain VRS Odometer test for determination of creep properties of a sensitive soft clay [4]. Jin et al. proposed a robust and effective evolutionary polynomial regression model for the correlation of creep index [5]. However, previous studies focused more on the relationship between the material composition and deformation of soil, and rarely combined with the groundwater change mode to explore creep characteristics of soil [6]. The effective stress induced by dewatering is different due to different groundwater table change, and the creep characteristics of soil are often different. The land subsidence induced by dewatering not only related to the properties of soil itself, but also closely related to the changes of groundwater table experienced by soil layers [7].

Therefore, taking the typical soil of fine sand in Shanghai's seventh layer as example, tests were conducted to investigate the creep deformation characteristics under different groundwater table changes. It is of great importance to reveal the mechanism of land subsidence induced by dewatering, and it is beneficial to strengthen the control of land subsidence.

\section{Test design}

\subsection{Soil}

The fine sand in Shanghai's seventh layer in was selected in the test, and the fine sand is often related to dewatering in deep foundation pit, so it is representative for the engineering in Shanghai. The location of sample is a deep foundation pit project in Shanghai. There are no significant industrial pumping and engineering construction activities in the sampling site in history, so the influence of the original ground settlement could be

"Corresponding author's e-mail: huangtianrong@succ.edu.cn 
ignored. The samples were taken from the site with a ring cutter, and the cutter was 30 square centimetre and 2 centimetre high. In addition, there were no disturbance during transportation, the basic physical and mechanical properties was listed in Table 1.

Table1. Basic properties

\begin{tabular}{lll}
\hline & \multicolumn{1}{c}{ Index of fine sand } & Value \\
\hline & $0.5 \mathrm{~mm} \sim 0.25 \mathrm{~mm}$ & 0.1 \\
\cline { 2 - 2 } & $0.25 \mathrm{~mm} \sim 0.075 \mathrm{~mm}$ & 61.2 \\
\cline { 2 - 2 } $\begin{array}{l}\text { Percentage of particle size } \\
(\%)\end{array}$ & $0.075 \mathrm{~mm} \sim 0.05 \mathrm{~mm}$ & 14.7 \\
\cline { 2 - 2 } & $0.05 \mathrm{~mm} \sim 0.01 \mathrm{~mm}$ & \\
\cline { 2 - 3 } & $0.01 \mathrm{~mm} \sim 0.005 \mathrm{~mm}$ & \\
\cline { 2 - 3 } & $<0.005 \mathrm{~mm}$ & 5.2 \\
Coefficient of non-uniformity & & 2.49 \\
Coefficient of curvature & & 31.5 \\
Internal friction angel $\left({ }^{\circ}\right)$ & & \\
\hline
\end{tabular}

\subsection{Equipment}

Since the land subsidence induced by dewatering was equal to vertical one-dimensional deformation, the creep characteristics could use one dimensional compression instrument to research [8]. The YS-I high-pressure consolidator is used as the test equipment. And this apparatus was produced in a famous manufacturer in China. And the dial indicator data is automatically collected by static strain collector, as shown in Figure 1.

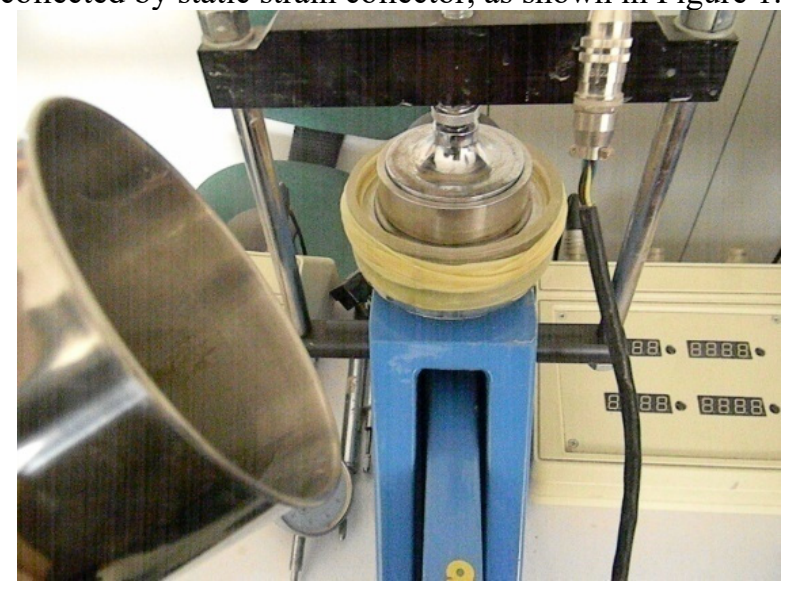

Fig 1. Test apparatus
The samples were dried by liquid nitrogen vacuum method after the test, then the Hitachi SU1510 was used to conduct scanning electron microscope, and mercury injection test was also carried out.

\section{Scheme}

There are three kinds of groundwater table change under the actual engineering conditions, that is, the effective stress induced by groundwater table change is less than, equal to or greater than the previous consolidation stress of soil. Since the in-situ stress of the Shanghai's seventh stratum is about $1000 \mathrm{kPa}$, the load of $2000 \mathrm{kPa}$ was implemented before the test. Then the repeated loading and unloading was adopted to simulate the decline and rise of groundwater table. The scheme was shown in Table 2.

Table2. Test schemes

\begin{tabular}{cll}
\hline Test & Preloading $(\mathrm{kPa})$ & Repeated loading and unloading $(\mathrm{kPa})$ \\
\hline S01 & 2000 & $500 \rightarrow 1000 \rightarrow 1500 \rightarrow 1000 \rightarrow 500$ \\
S02 & 2000 & $500 \rightarrow 1000 \rightarrow 1500 \rightarrow 2000 \rightarrow 1500 \rightarrow 1000 \rightarrow 500$ \\
S03 & 2000 & $500 \rightarrow 1000 \rightarrow 1500 \rightarrow 2000 \rightarrow 2500 \rightarrow 2000 \rightarrow 1500 \rightarrow 1000 \rightarrow 500$ \\
\hline
\end{tabular}

The test used the stress-controlled mode. In addition, the standard for stability is that the deformation is less than $0.005 \mathrm{~mm}$ per day, and the specific test operation could refer to the literature [9]. 


\section{Macro structure analysis}

\subsection{Initial loading}

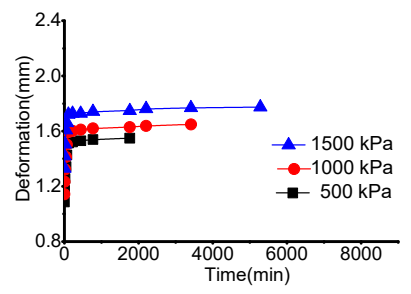

(a) $\mathrm{S} 01$
According to the test scheme, the samples were preloaded with $2000 \mathrm{kPa}$, and then conducted the repeated loading and unloading gradually until its final stabilization. That is to simulate the influence of groundwater table change on the creep of soil. Figure 2 shows the deformation duration curves of samples under initial loading.

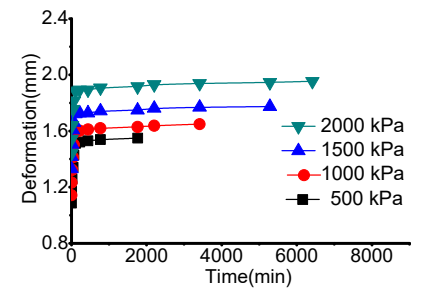

(b) $\mathrm{S} 02$
Fig 2. Creep curve under initial loading

As indicated in Figure.2, with the decline of groundwater table and the increase of effective stress, the deformation of the samples increases gradually, but the increase rate becomes smaller and smaller. Due to the preloading load of $2000 \mathrm{kPa}$, the deformations of the three specimens under $500 \mathrm{kPa}, 1000 \mathrm{kPa}$ and $1500 \mathrm{kPa}$ are very close and less than $1.8 \mathrm{~mm}$. However, when the load reaches $2000 \mathrm{kPa}$ and $2500 \mathrm{kPa}$, the compression deformation of fine sand sample reaches $1.908 \mathrm{~mm}$ and $2.160 \mathrm{~mm}$ respectively, which indicates that there is still a large creep when the effective stress caused by

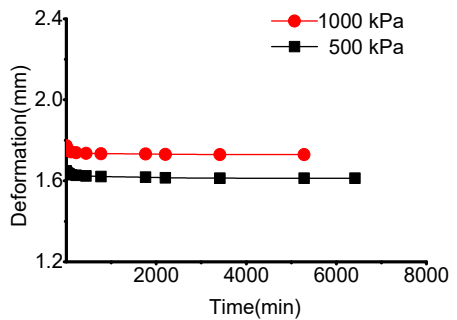

(a) S01

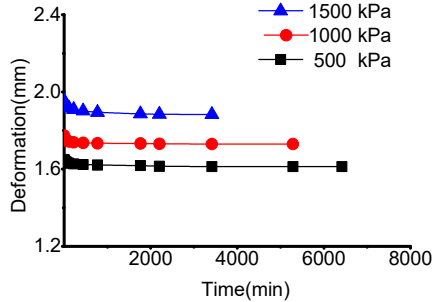

(b) $\mathrm{S} 02$

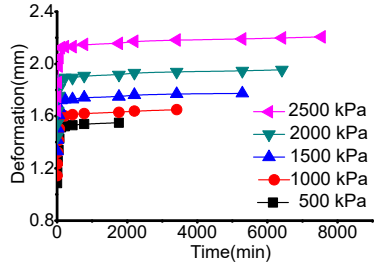

(c) $\mathrm{S} 03$ groundwater table change is greater than or equal to the consolidation stress in the early stage.

\subsection{Initial unloading}

When the last stage of initial loading is stable, the samples are unloaded gradually to simulate the groundwater rising. Figure. 3 shows the deformation of S01, S02 and S03 during initial unloading.

Fig 3. Creep curve under initial unloading

As shown in Figure.3, with the rise of groundwater table and the decrease of effective stress, the rebound occurs in the sample. At the rebound rate was big in first then starts to decrease after time accumulated. The rebound deformation of soil sample gradually tends to a certain value in the end, and the time to reach stability is shorter than that under loading. The time of stability of rebound is short and the amount of rebound is small when the stress is higher than previous consolidation stress. But the amount of rebound is very small comparing with the total deformation of soil; and the most of the deformation of soil under load is irrecoverable residual deformation.

\subsection{Repeated loading and unloading}

In order to study the deformation characteristics, repeated loading and unloading were carried out according to the test scheme, and the deformation duration curves were shown in Figure.4.

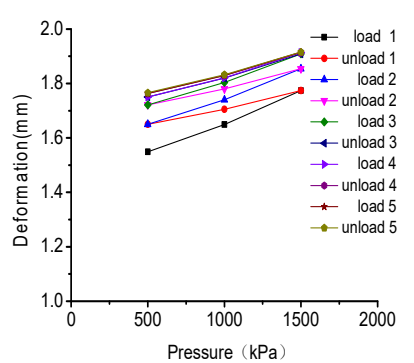

(a) $\mathrm{S} 01$

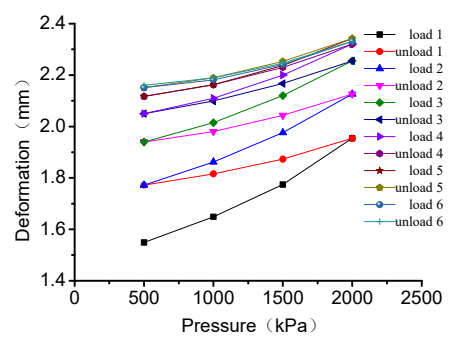

(b) $\mathrm{S} 02$

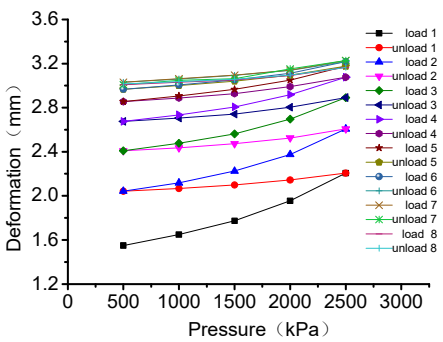

(c) $\mathrm{S} 03$

Fig 4. Deformation duration curve 
It can be seen from Figure. 4 that the deformation of fine sand sample increases with repeated loading and unloading, but the increase rate decreases with the repeated times. And the deformation tends to be smaller and smaller, which indicates that the secondary consolidation is also weakening with repeated loading and unloading. Comparing the three samples, the secondary consolidation of sample S01 tends to be stable after five cycles because the repeated load is less than the preloading of $2000 \mathrm{kPa}$. Moreover, the deformation of sample S02 is larger in repeated loading cycles because the maximum load is equal to the preloading of $2000 \mathrm{kPa}$, but it gradually becomes stable after six cycles and total deformation is $2.160 \mathrm{~mm}$. The deformation of sample S03 is $3.016 \mathrm{~mm}$ when it reached its stabilization, because the

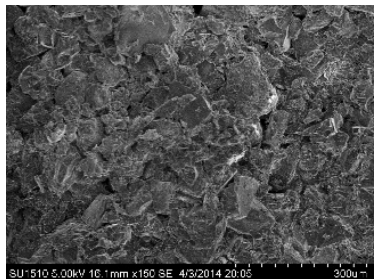

(a)Undisturbed

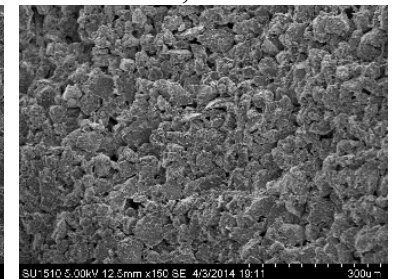

(b) S01

load is greater than the preloading. In addition, the initial unloading rebound of sample S03 is only $28 \%$ in the first loading, and the sample tends to be stable after 8 cycles.

\section{Microstructure analysis}

\subsection{Scanning electron microscope}

In order to reveal the microscopic characteristics of fine sand, a representative SEM picture was selected from the scanning electron microscope pictures of the vertical section of undisturbed soil and three samples, as shown in Figure.5.

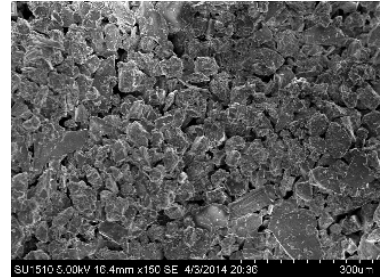

(c) S02

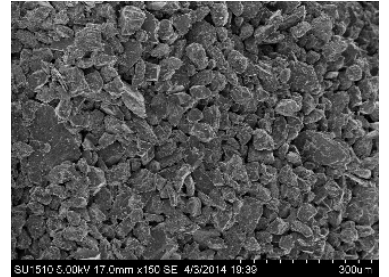

(d) $\mathrm{S} 03$

Fig 5. SEM image of fine sand

As Figure.5 indicates, when the repeated load is less than the initial consolidation stress, the deformation is mainly elastic, and the particle shape of the sample S01 is similar to the undisturbed soil. When the repeated load is equal to pre consolidation stress, the deformation of sample S02 is mainly viscoelastic plastic, the adjustment range of sample is obviously increased, the sample particles have obvious slip, and some particles overlap to form new pores. Similarly, the adjustment range of the sample S03 is larger, the particle slip is more obvious, the overlapping and protruding particles increased, and the deformation is mainly viscoelastic. However, the adjustment of the samples included mainly particle position. Therefore, the creep deformation of fine sand particles is not mainly due to the structural damage of soil particles, but the sliding of particles.

From previous research $[10,11]$, the creep of sand mainly includes two aspects: sliding of sand particles along the indirect contact surface and particle breakage. However, for the fine sand in Shanghai's seventh layer is a quaternary fluvial sediment, the mineral composition is mainly quartz [12]. Under the load induced by groundwater table change, the particles are constantly adjusted and displaced and then continuing to adjust and move under the load, which is also a good explanation for the creep of fine sand in Shanghai. Therefore, the creep of fine sand in Shanghai's seventh layer is mainly due to the slip of particles rather than the breaking of particles.

\subsection{Mercury intrusion test}

After data processing, the distribution curve of particle size was obtained from the mercury intrusion test, which as shown in Figure.6.

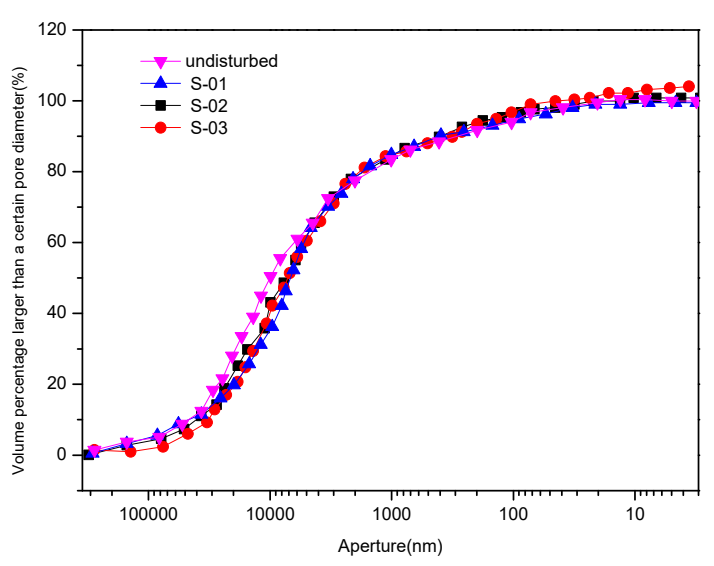

Fig 6. Pore size distribution

From the Figure.6, the pore size of samples mainly concentrated in the range of $100-20000 \mathrm{~nm}$. The percentage of large pores with radius greater than $50 \mathrm{~nm}$ is more than $95 \%$. Therefore, the fine sand has strong bearing capacity and are not easy to be broken. For the pore size distribution curves, it can be seen that the four curves of samples are basically overlapped together, which indicates that the particle size distribution of the fine sand is mainly unchanged after creep test, and the percentage of macrospores remained at about $95 \%$. Jerry had pointed out that, Ordinary sand usually takes more than $1 \mathrm{MPa}$ to produce crushing due to the large bearing capacity of sand [13]. And the load induced by dewatering of 1 meter is only $5 \mathrm{kPa}$, thus the force induced by water table change could only produce elastic deformation. However, recent studies have shown that sand also has obvious creep in Shanghai stratum, and its deformation could not be ignored [14]. This research could explain the basic reason of creep of fine sand under the load induced by the groundwater table change in a reasonable way. 


\section{Conclusion}

Based on macro tests and microstructure analysis, the main conclusions includes as following.

(1) The creep of fine sand connects closely with groundwater table change. When the load induced by groundwater table change is less than previous consolidation stress, the deformation is mainly elastic. When the load induced by groundwater table change is greater than previous consolidation stress, the compression deformation is large and the rebound is small; and when is equal to the previous consolidation stress, it is mainly viscoelastic plastic deformation.

(2) The creep of fine sand is mainly the slip of particles, not the breakage of particles. The soil particles slide along the indirect contact surface of the particles due to extrusion, which causes the relative displacement and secondary consolidation deformation.

(3) The pore size distribution of fine sand reminded unchanged before and after the test, which reflects the creep mechanism of silt quantitatively. The microstructure of particle structure and contact mode is the essential reason for the difference of macro creep characteristics.

(4) The land subsidence induced by foundation pit dewatering includes a variety of deformation characteristics of soil. The actual project should divide different zones and control the land subsidence.

\section{References}

1. Xu X, Cui Z. (2020) Investigation of a fractional derivative creep model of clay and its numerical implementation. Computers and Geotechnics, 119(5):156-182.

2. Li J, Yang Y. (2018).Creep behaviour of unsaturated reticulate red clay under matric suction. KSCE Journal of Civil Engineering, 22 (2):582-587.

3. Zhu Q, Yin Z, Hicher P. (2016). Nonlinearity of onedimensional creep characteristics of soft clays. Acta Geotechnica, 11 (4):887-900.

4. Lnsivaara T. (2020) Determination of Creep Properties of Clays from VRS Odometer Tests. Geotechnical and Geological Engineering, 38 (3):1857-1871.

5. Jin $Y, Y$ in Z,Zhou W. (2019)A single-objective EPR based model for creep index of soft clays considering L2 regularization. Engineering Geology, 248(8):242255.

6. Yun Z, Xue Y, Wu J. (2011) Experimental study on creep deformation of saturated cohesive soil. Chinese Journal of Geotechnical mechanics, 3:672-683.

7. Xue Y. (2012). On groundwater overdraft and land subsidence. Chinese Journal of Groundwater, 34 (6): $1-5$.

8. Gong S,Ye W, Chen H. (2008). Ground subsidence evaluation theory and method for deep foundation pit engineering in Shanghai. Chinese Journal of geological hazards and prevention. 2008, 19 (4): 5560 .
9. Yuan J. (2003). Geotechnical Test and Principle.Tongji University Press, Shanghai.

10. Mcdowell G. (2003). Micromechanics of creep granular materials. Geotechnics, 53(10):915-916.

11. Lade P, Liu C. (1998). Experimental study of drained creep behaviour of sand. Journal of Engineering Mechanics, 124(8):912-920.

12. He M. (1989). Clay minerals, microstructure and land subsidence of shallow soil in Shanghai urban area. Shanghai geology, 15(4):31-40.

13. Jerry A, Yamamuro,P. (1996).One dimensional compression of sand at high pressure. Journal of Geotechnical Engineering, 122(2):147-154.

14. Shi X, Xue Y, Wu J. (2006). Study on compression deformation characteristics of aquifer system in Changzhou area. Chinese Journal of Hydrogeology and engineering geology, 33 (3): 1-6. 